\title{
Absence of Exercise-Induced Hypoglycaemia in Type I (Insulin-Dependent) Diabetic Patients During Maintenance of Normoglycaemia by Short-Term, Open-Loop Insulin Infusion
}

\author{
M.J. Martin ${ }^{1}$, D.C. Robbins ${ }^{1}$, 2 , R. Bergenstal ${ }^{1}$, B. LaGrange ${ }^{2}$ and A.H. Rubenstein ${ }^{1}$ \\ ${ }^{1}$ Endocrinology Section, Department of Medicine, University of Chicago, Chicago, Illinois and \\ ${ }^{2}$ The Metabolic Unit, Department of Medicine, University of Vermont, Burlington, Vermont, USA
}

\begin{abstract}
Summary. To assess the risk and possible mechanisms of hypoglycaemia during moderate exercise in Type I (insulin-dependent) diabetic patients receiving constant insulin infusion, five insulin-dependent male diabetic patients were exercised $18 \mathrm{~h}$ after their last meal and $30 \mathrm{~h}$ after their last injection of intermediate acting insulin. Intravenous insulin was initially delivered via a closed-loop infusion system programmed to lower mean blood glucose from $11.3 \pm 1.8$ to $4.8 \pm 0.4 \mathrm{mmol} / 1$ over approximately $3.5 \mathrm{~h}$. Blood glucose was then maintained at this level for $4 \mathrm{~h}$. At this time, the closed-loop infusion was discontinued and replaced by an open-loop system. The average amount of insulin infused per min during the $4 \mathrm{~h}$ normoglycaemic closed-loop period was calculated and this amount was infused at a constant rate during both a $30 \mathrm{~min}$ period of exercise on a bicycle ergometer (approximately $65 \%$ maximum oxygen uptake) and a $30 \mathrm{~min}$ rest period which followed. Five non-
\end{abstract}

diabetic males served as control subjects. Despite significantly higher free insulin concentrations $(p<0.05)$ and identical preexercise blood glucose concentrations, blood glucose rose during exercise only in the diabetic group $(0.5 \pm 0.2 \mathrm{mmol} / 1 ; p<$ $0.01)$. Changes in the serum concentrations of lactate, glycerol, glucagon, cortisol, non-esterified fatty acids and growth hormone were similar in the two groups and did not account for the increment of blood glucose in the diabetic patients. Betahydroxybutyrate concentrations were, however, higher in the diabetic patients at the onset of exercise $(p<0.01)$ and decreased significantly more than the control subjects during exercise. We conclude that exercise under these conditions in diabetic patients is not attended by hypoglycaemia.

Key words: Type I diabetes, exercise, open-loop insulin infusion.
One method of normalizing blood glucose is an openloop insulin infusion pump which delivers insulin at a constant rate with pulses of insulin before meals $[1,2]$ without immediate regard to the concentration of blood glucose. This therapy may put patients at risk of hypoglycaemia: those most at risk would appear to be Type I patients whose exercise and meal plans may be most unpredictable.

There are several reasons why exercise might cause a fall in blood glucose in diabetic subjects who receive a constant insulin infusion. Firstly, free insulin concentrations are usually higher in the such patients compared with non-diabetic subjects [3]. Secondly, unlike normal subjects in whom insulin release declines during exercise [4], there is no decline in the rate of insulin infusion given via a constant open-loop infusion apparatus. Thus, high insulin levels in combination with increased glucose consumption could be expected to produce hypoglycaemia. On the other hand, portal vein insulin concentrations produced by these devices may be low, relative to those in the non-diabetic. Thus, despite increased pe- ripheral concentrations, the amount of insulin reaching the liver may be insufficient to regulate hepatic glucose production appropriately. Under these circumstances, blood glucose may even rise during moderate exercise.

The purpose of this study was to assess the effect of exercise in Type I diabetic patients receiving a constant, open-loop insulin infusion programmed to achieve and maintain normoglycaemia while at rest.

\section{Subjects and Methods}

The study was conducted at the University of Chicago's Clinical Research Centre. Informed consent was obtained from each subject before the investigation. Five male Type I diabetic patients (age $30 \pm$ 5 years, duration of diabetes $8 \pm 2$ years), without clinically detectable complications, and five age-matched, healthy male control subjects were studied. Insulin regimens of the diabetic subjects are shown in Table 1. All subjects were accustomed to moderate, erratic, physical exercise but none engaged in regular strenuous, competitive exercise. The subjects were instructed to eat their normal diet until the evening before the study. Each diabetic took his normal morning insulin on the day before the study, but, thereafter, intermediate and long-acting insulins were withheld. 
Table 1. Insulin requirements in the diabetic group

\begin{tabular}{llrl}
\hline Subject & Usual morning dose & $\begin{array}{l}\text { Usual evening dose } \\
(\text { withheld before study) }\end{array}$ & $\begin{array}{l}\text { Insulin dose } \\
\left(\mathrm{Units}^{\mathrm{k}} \mathrm{kg}^{-1} \cdot \mathrm{d}^{-1}\right)\end{array}$ \\
\hline 1 & $40 \mathrm{U} \mathrm{NPH}$ & & 0.71 \\
2 & $34 \mathrm{U} \mathrm{NPH}$ & $5 \mathrm{U} \mathrm{NPH} ; 5 \mathrm{U} \mathrm{CZI}$ & 0.49 \\
3 & $10 \mathrm{U} \mathrm{NPH} ; 5 \mathrm{U} \mathrm{CZI}$ & 0.33 \\
4 & $42 \mathrm{U} \mathrm{NPH} ; 6 \mathrm{U} \mathrm{CZI}$ & $12 \mathrm{U} \mathrm{NPH} ; 6 \mathrm{U} \mathrm{CZI}$ & 0.87 \\
5 & $55 \mathrm{UNPH}$ & & 0.74 \\
\hline
\end{tabular}

${ }^{a}$ crystalline zinc insulin

\section{Exercise}

To determine the ergometer tension that would give a pulse rate of approximately 150 beats $/ \mathrm{min}$ when pedalling at $20-25 \mathrm{~km} / \mathrm{h}$, each subject exercised before the study on a stationary bicycle ergometer for $7 \mathrm{~min}$. This rate of exercise corresponds to approximately $65 \%$ of maximum oxygen uptake [5]. This tension and pedalling rate were kept constant throughout the 30-min exercise period. During rest periods, subjects were in a sitting position.

\section{Glucose Controlled Insulin Infusion System}

The artificial B cell [Biostator, glucose-controlled insulin infusion system], Life Science Instruments, Miles Laboratories, Elkhart, Indiana, USA], and the regulating algorithms have been described fully elsewhere $[6,7]$. Briefly, blood is continuously withdrawn at a rate of $2 \mathrm{ml} / \mathrm{h}$ through a double lumen cannula placed in an antecubital vein. On the basis of continuous whole blood glucose analyses, the machine infuses insulin and/or glucose to maintain normoglycaemia. In this experiment only insulin was infused.

\section{Experimental Protocol}

After an overnight fast of at least $12 \mathrm{~h}$ and $24 \mathrm{~h}$ after the last injection of intermediate acting insulin, three indwelling cannulae were inserted into arm veins of each diabetic subject. After 15 min rest, baseline blood samples were obtained. The glucose-controlled insulin infusion was started and blood glucose concentrations were decreased to approximately $4.4-5.0 \mathrm{mmol} / 1$. The average time required to normalize the blood glucose was $3.5 \mathrm{~h}$. Blood glucose concentrations were maintained at this level for at least $1 \mathrm{~h}$ when a second set of blood samples was obtained. Blood glucose was then maintained at this level for $4 \mathrm{~h}$ by infusion of insulin according to the glucose-controlled insulin infusion system algorithm. The average rate of the insulin infusion needed during these $4 \mathrm{~h}$ was calculated $\left(68 \pm 25 \mu \mathrm{U} \cdot \mathrm{kg}^{-1} \cdot \mathrm{min}^{-1}\right)$ and this amount was then given throughout the 30 -min exercise and post-exercise rest period as an open-loop, constant-rate infusion.

Non-diabetic control subjects were studied after an overnight fast during a similar protocol. They were not attached to the glucose-controlled insulin infusion system but had one indwelling canmula in a forearm vein to facilitate blood collection. A volume of normal saline was infused equal to that administered to the diabetic group.

\section{Analytical Methods}

Glucose concentrations were determined by kinetic assay using hexokinase [8]. Free insulin and C-peptide [9] were determined by radioimmunoassay. Glucagon was assayed using $30 \mathrm{~K}$ antiserum [10]. A colorometric method was used to measure non-esterified fatty acid concentrations [11]. Enzymatic methods were used to determine lactate, $\beta$-hydroxybutyrate and glycerol concentrations [12]. Growth hormone [13] and cortisol [14] were determined using radioimmunoassay and competitive protein binding assay, respectively.

The sensitivities and intra-assay coefficients of variation for several of the assays were, respectively: insulin $1.0 \mathrm{mU} / 1,5.7 \%$; C-peptide
$0.02 \mathrm{pmol} / 1,7.5 \%$; glucagon $5 \mathrm{pg} / \mathrm{ml}, 8.8 \% ; \beta$-hydroxybutyrate $20 \mu \mathrm{mol} / 1,4.4 \%$; glycerol $20 \mu \mathrm{mol} / 1,4.5 \%$; growth hormone $0.07 \mathrm{ng} /$ $\mathrm{ml}, 4.0 \%$; cortisol $0.1 \mathrm{nmol} / 1,2.0 \%$.

\section{Statistical Methods}

Results are expressed as mean \pm SEM. Significance of the difference between two mean values was calculated using the Student's t-test. The mean change between any two time points was calculated by averaging the changes for each subject (paired t-test).

\section{Results}

To achieve euglycaemia in the diabetic subjects, an average of $3620 \pm 932 \mathrm{mU}$ of insulin was required. Once euglycaemia was achieved, $1065 \pm 350 \mathrm{mU}$ of insulin $\left(68 \pm 26 \mu \mathrm{U} \cdot \mathrm{kg}^{-1} \cdot \mathrm{min}^{-1}\right)$ were required to maintain the plasma glucose concentrations between 4.4 and $5.0 \mathrm{mmol} / 1$.

There were no significant differences in heart rates between the normal and diabetic subjects at any time point (Table 2). The most rapid pulse for both diabetic (154 \pm 8 beats/min) and control subjects ( $155 \pm 8$ beats/ min) occurred at the end of the exercise period.

Blood glucose values during the study are shown in Figure 1. At the onset of the experiment the blood glucose concentrations of the diabetic patients (11.3 \pm $1.8 \mathrm{mmol} / \mathrm{l})$ were significantly higher than the normal subjects $(5.1 \pm 0.1 ; p<0.02)$. Thereafter, there were no significant differences in blood glucose levels between the two groups before exercise. However, the groups differed in their response to exercise. The mean rise in blood glucose for the diabetic patients $(0.6 \pm$ $0.2 \mathrm{mmol} / 1)$ reached statistical significance $(p<0.01)$, while that of the control subjects $(0.1 \pm 0.1 \mathrm{mmol} / \mathrm{l})$ did not. These changes were also significantly different when the two groups were compared with each other $(p<0.02)$. During the $30 \mathrm{~min}$ of rest following exercise, plasma glucose continued to rise in the diabetic group, but only slightly $(0.2 \pm 0.1 \mathrm{mmol} / \mathrm{l})$.

The control group had a gradual but significant decline in the concentration of immunoreactive free insulin during the pre-exercise period $(p<0.05)$ (Table 2). A further decline was observed during exercise. Free immunoreactive insulin concentrations in the diabetic group were several-fold higher at all time points com- 
pared with the control group and were constant throughout the experimental period $(p<0.05)$.

The non-esterified fatty acid (NEFA) concentrations (Fig.2) were higher in the diabetic subjects at all time points, but the difference between groups was significant only before normalization of blood glucose. The NEFA concentrations in both groups increased during the period before exercise. During exercise, NEFA concentrations declined during the first $10 \mathrm{~min}$, then rose in both groups. The late rise in NEFA concentrations seen during the last $20 \mathrm{~min}$ of exercise tended to be greater in the diabetic patients $(0.31 \pm 0.09 \mathrm{mmol} / 1 ; p<0.02)$ than the control subjects $(0.14 \pm 0.02 \mathrm{mmol} / 1 ; p<0.01)$, but the difference between the groups was not statistically significant. The decline in NEFA concentration during the first $10 \mathrm{~min}$ of exercise was not significant.

$\beta$-hydroxybutyrate concentrations (Fig. 2) were markedly higher in the diabetic patients at all times. There was a gradual rise in the concentration before exercise in both the diabetic $(0.39 \pm 0.10 \mathrm{mmol} / 1 ; p<$ $0.01)$ and control $(0.10 \pm 0.05 \mathrm{mmol} / 1)$ groups. The magnitude of the increase in the diabetic patients was greater than in the control group $(p<0.02)$. During exercise, $\beta$-hydroxybutyrate concentrations initially decreased in both groups. The mean fall was much larger in the diabetic $(0.21 \pm 0.03 \mathrm{mmol} / 1 ; p<0.001)$ than the control group $(0.07 \pm 0.03 \mathrm{mmol} / 1 ; p<0.05)$. Furthermore, these changes were significantly different from one another $(p<0.02)$.

There were no significant differences in the glycerol concentrations between the two groups (Fig. 2). The mean rise during exercise tended to be higher in the diabetic $(0.32 \pm 0.06 \mathrm{mmol} / 1 ; p<0.001)$ than the control

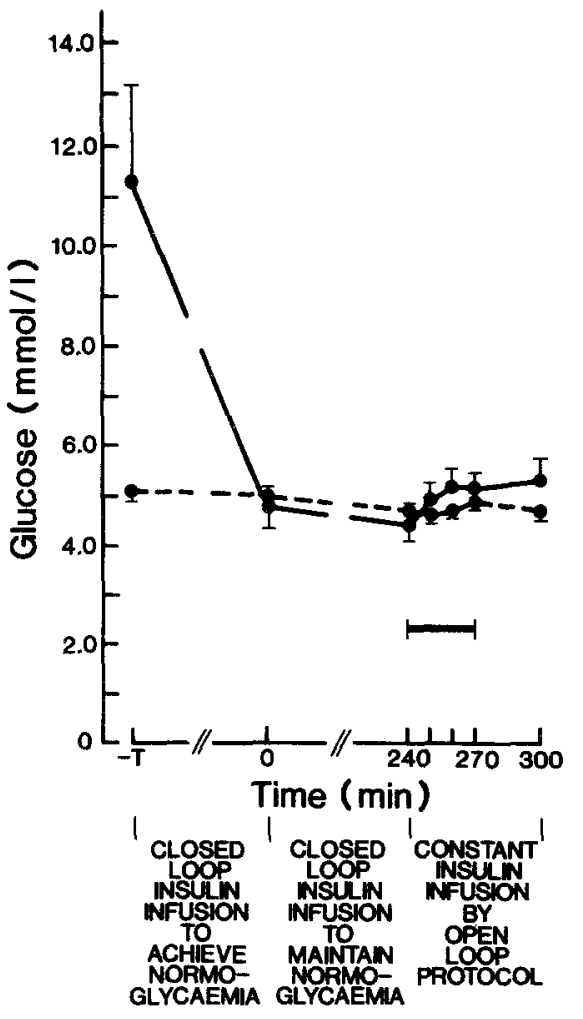

Fig. 1. Blood glucose concentrations in the diabetic patients (-) and control subjects (--- ) are shown. The 30 -min period of exercise beginning at $240 \mathrm{~min}$ and terminating at $270 \mathrm{~min}$ is marked by the horizontal bar. A significant difference between the groups before exercise occurred only in the first measurement $(p<0.02)$. The mean rise in blood glucose in the diabetic patients during exercise was significant $(p<0.01)$ while no change was discernable in the control group. These exercise-associated changes were different when the two groups were compared with each other $(p<0.02)$

Table 2. Heart rate and concentration of various substances in diabetic patients and control subjects

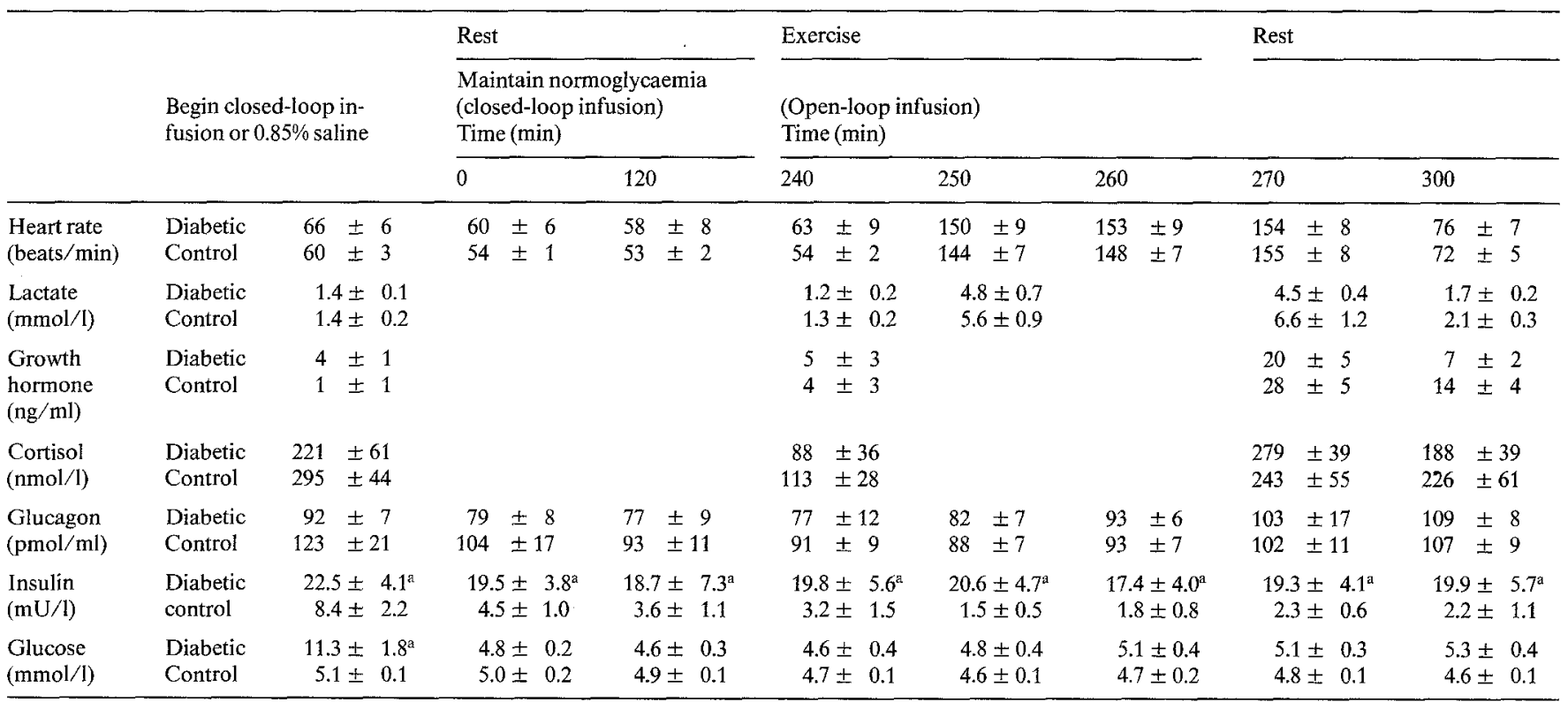

Results expressed as mean $\pm \mathrm{SEM}$; ${ }^{\text {a }}$ Indicates $p<0.05$ between groups 

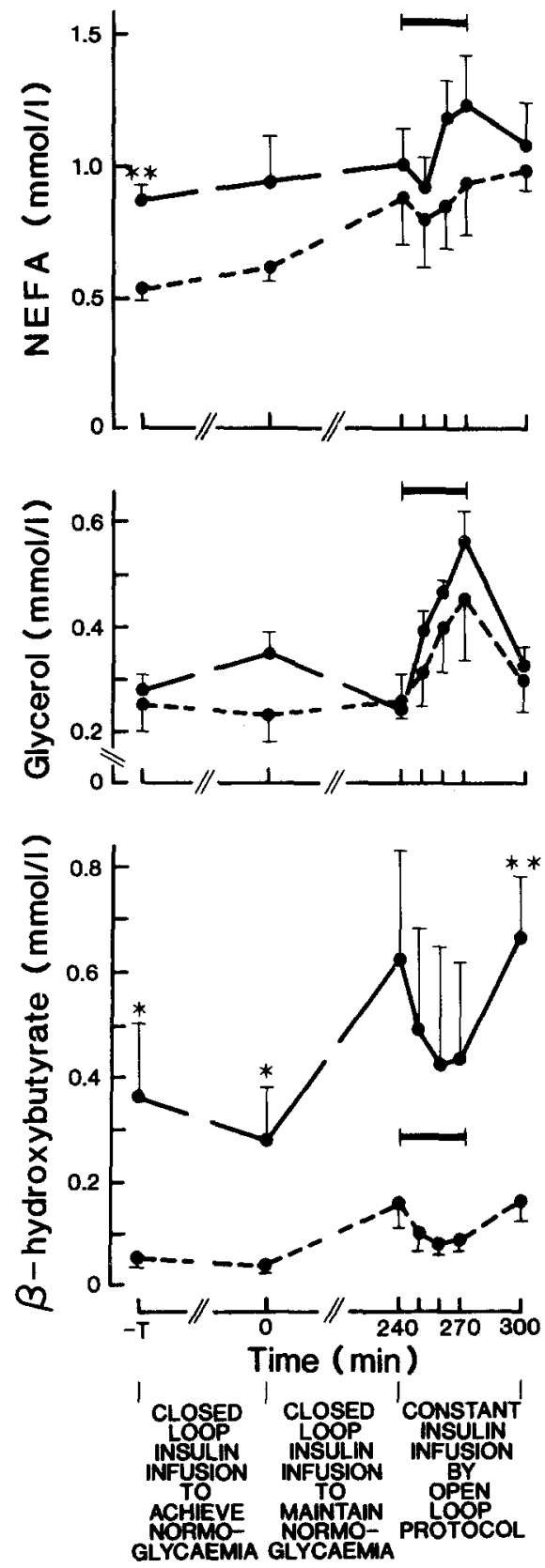

Fig. 2. Serum concentrations of non-esterified free fatty acids (NEFA), glycerol and $\beta$-hydroxybutyrate in the diabetic patients $(-0)$ and control subjects $(---)$ are shown. ${ }^{*} p<0.05 ; * * p<0.01$ significant differences between groups

groups $(0.20 \pm 0.08 \mathrm{mmol} / 1 ; p<0.05)$, but the difference between the groups was not significant.

There were no detectable differences between the two groups at any time in concentrations of lactate (Table 2). There was a significant mean rise during exercise in both the diabetic $(3.3 \pm 0.6 \mathrm{mmol} / 1 ; p<0.01)$ and control groups $(5.4 \pm 1.2 \mathrm{mmol} / 1 ; p<0.01)$. These changes, however, were not significantly different from one another. After the 30-min post-exercise rest period, lactate concentrations in both groups returned to preexercise values.
In one of the five diabetic patients a circulating antiglucagon antibody prevented measurements of plasma glucagon. In the others pre-exercise glucagon concentrations tended to be lower than those of the control subjects (Table 2), but the difference between the groups was not significant. In both groups, plasma glucagon concentrations rose during exercise, but the increment was not significant. C-peptide concentrations in the diabetic patients (data not shown) were at or below the detection limits of the assay $(0.02 \mathrm{pmol} / \mathrm{l})$ throughout the protocol.

The pre-exercise concentrations of growth hormone tended to be higher in the diabetic subjects, although the differences were not significant (Table 2). There was a significant rise in the growth hormone concentrations during exercise in both the diabetic $(15 \pm 6 \mathrm{ng} / \mathrm{ml} ; p<$ $0.05)$ and the control groups $(24 \pm 7 \mathrm{ng} / \mathrm{ml} ; p<0.01)$. Serum cortisol concentrations at each time point were not significantly different between the two groups (Table 2). There was a significant increase during exercise in both the diabetic $(193 \pm 63 \mathrm{nmol} / 1 ; p<0.05)$ and control groups $(130 \pm 33 \mathrm{nmol} / 1 ; p<0.02)$.

\section{Discussion}

Although the blood glucose in normal subjects can increase by 1.1 to $1.7 \mathrm{mmol} / \mathrm{I}$ with vigorous exercise [4] and decrease 0.6 to $2.2 \mathrm{mmol} / 1$ with exercise continuing beyond $90 \mathrm{~min}[15,16]$, there is little change during shortterm, mild or moderate exercise $[4,17]$. This is due to the equalization of glucose production and utilization.

In diabetic subjects and experimental animals, the concentration of circulating insulin present during exercise is an important factor in determining whether blood glucose will rise, fall or remain constant during exercise. A small, but critical concentration of insulin is essential for stimulation of glucose utilization during exercise [18, 19]. When diabetic dogs were subjected to exercise $27 \mathrm{~h}$ after their last insulin injection, blood glucose rose sharply due to increased glucose production without a concomitant increase in glucose utilization by exercising muscle [20]. Similar elevations in plasma glucose concentrations have also been reported in insulin deficient diabetic patients during exercise [21-23].

In contrast to the insulin-deficient model of exercise, over-insulinized diabetic animals exhibit a fall in plasma glucose during exercise. When depancreatectomized dogs are given a subcutaneous injection of insulin before exercise, plasma insulin levels are elevated, and there is a significant fall in plasma glucose concentrations due to a mismatch of glucose uptake (which was similar to normal dogs during exercise) and hepatic glucose production (which was decreased from that found in normal dogs) [24-26]. Zinman et al. [27] demonstrated this same effect in diabetic subjects receiving subcutaneous insulin injections before exercise. Thus, appropriate insulin concentrations during exercise allow optimal glucose utilization by peripheral tissues and appropriate regula- 
tion of hepatic glucose production. There is then equilization of glucose production and utilization during exercise, and blood glucose concentrations are relatively stable [28, 29]. In support of this concept, Zinman et al. [30] have shown that exercising diabetic patients have stable blood glucose concentrations during constant insulin infusion which produces blood glucose concentrations of $6.7 \mathrm{mmol} / 1$. Under these circumstances, glucose production and disappearance rose synchronously and were similar to the responses observed in normal subjects.

In light of these observations in the exercising diabetic patients, the concentrations of free immunoreactive insulin achieved in this study are critical in interpreting the glycaemic response we have described. Obviously, adequate amounts of insulin were infused to produce stable euglycaemia in each diabetic subject while at rest. Furthermore, the concentrations of free immunoreactive insulin in the diabetic subjects were similar to those reported by others under similar circumstances [3]. Yet, despite apparently adequate insulinization, the glycaemic response during exercise reflects a mild imbalance between glucose production and consumption. Our data do not permit us to determine whether glucose production was inadequately suppressed, peripheral glucose consumption relatively diminished, or whether both mechanisms contributed to the glycaemic response.

The rise in plasma glucose in the diabetic subjects during exercise may have been due to greater amounts or greater effects of circulating stress hormones. Those we measured (glucagon, cortisol, growth hormone), however, were not different in the control and diabetic groups, at the beginning or end of exercise. Although peripheral concentrations do not necessarily reflect portal concentrations or tissue sensitivity, these data offer no support for the contention that these hormones accounted for the observed rise in plasma glucose. A possible role for catecholamines cannot be excluded. Gluconeogenic precursors or other non-carbohydrate fuels may have also contributed to the exercise-induced glycaemia. In particular, our data suggest relatively greater consumption of $\beta$-hydroxybutyrate by the diabetic group. The pattern of response in both groups was similar and consisted of a decline in $\beta$-hydroxybutyrate concentration during exercise and an increase after exercise. The pattern is consistent with the observations of other investigators [29, 31]. The diabetic patients, however, had markedly higher levels of $\beta$-hydroxybutyrate throughout the experiment and a relatively greater decrease during exercise suggesting increased utilization of ketone bodies as an energy substrate $[32,33]$. Higher serum NEFA concentrations and comparatively lower portal to systemic insulin ratios (as a consequence of intravenous, rather than intraportal infusion of insulin) may explain this observation. An increased utilization of $\beta$-hydroxybutyrate in the diabetic group may have led to diminished glucose utilization and, at least in part, contributed to the exercise-induced rise in blood glucose.
The higher NEFA concentrations found in the diabetic group have been reported by other investigators $[21,29]$. Fasting probably caused the NEFA levels to rise in both groups before exercise while the effect of the insulin infusion tended to narrow the difference between the groups. The concentrations of glycerol before exercise and the response of this substrate during exercise was similar in both groups and consistent with results previously reported for normal subjects $[17,31]$.

Other studies have demonstrated an abnormally high lactate concentration during exercise in diabetic subjects $[21,29,31]$. During exercise with constant insulin infusion, Murray et al. [31] reported lactate levels in diabetic patients twice as high as in healthy controls. There were, however, no differences in the lactate concentrations recorded during exercise in the two groups in the present study. This may have been due to the achievement of normoglycaemia.

Open-loop insulin infusion pumps can maintain near-normal blood glucose levels in Type I diabetic patients at rest or during moderate activity $[1,2]$. In this study, we have extended the results of Zinman et al. [30] to show that short-term, continuous, intravenous insulin administration does not produce hypoglycaemia in fasting patients during or immediately after exercise, even when normoglycaemia is maintained. Further study is needed before the results of this experience can be extended to diabetic subjects undergoing chronic insulin infusion therapy and stresses other than exercise. Adaptation of muscle, fat or liver to much more prolonged maintenance of euglycaemia may result in different responses. Nevertheless, the assumption that hypoglycaemia will be an invariable occurrence when normoglycaemic diabetic patients engage in vigorous exercise or are subjected to stress is certainly not warranted.

\section{References}

1. Tamborlane WV, Sherwin RS, Genel M, Felig P (1979) Reduction to normal of plasma glucose in juvenile diabetes by subcutaneous administration of insulin with a portable infusion pump. $\mathrm{N}$ Engl $\mathbf{J}$ Med 300: 573-578

2. Tamborlane WV, Sherwin RS, Genel M, Felig P(1979) Restoration of normal lipid and amino acid metabolism in diabetic patients treated with a portable insulin-infusion pump. Lancet 1:1258-1261

3. Rizza RA, Gerich JE, Haymond MW, Westland RE, Hall LD, Clemens AH, Service FJ (1980) Control of blood sugar in insulin dependent diabetics: Comparison of an artifical endocrine pancreas continuous subcutaneous insulin infusion, and intensified conventional therapy. N Engl J Med 303: 1313-1318

4. Felig P, Wahren J (1975) Fuel homeostasis in exercise. N Engl J Med 293: 1078-1084

5. Åstrand PO, Rhyming I (1954) A nomogram for calculation of aerobic capacity (physical fitness) from pulse rate during submaximal work. J Appl Physiol 7: 218-221

6. Santiago JV, Clemens AH, Clarke WL, Kipnis DM (1979) Closedloop and open-loop devices for blood glucose control in normal and diabetic subjects. Diabetes 28:71-81

7. Clemens AH, Chang PH, Myers RW (1977) The development of Biostator, a glucose controlled insulin infusion system (GCIIS). Horm Metab Res Suppl 7:23-33 
8. Slein MW (1963) D-Glucose: Determination with hexokinase and glucose-6-phosphate dehydrogenase. In: Bergmeyer HU (ed) Methods of enzymatic analysis, $1^{\text {st }}$ edn, Academic Press, New York, pp 117-123

9. Starr JI, Horwitz DL, Rubenstein AH, Mako ME (1979) Insulin, proinsulin, and C-peptide. In: Jaffe BM and Behrman HR (eds) Methods of hormone radioimmunoassay, 2nd edn, Academic Press, New York, pp 613-642

10. Unger RH, Aguilar-Parada E, Muller WA, Eisentraut AM (1970) Studies of pancreatic alpha cell function in normal and diabetic subjects. J Clin Invest 49:837-848

11. Mikac-Devic D, Stankovic H, Boskovic K (1973) A method for determination of free fatty acids in serum. Clin Chim Acta 45:55-59

12. Varley H (1967) Practical clinical biochemistry. London and Interscience Books, New York pp 618-619

13. Odell WD, Rayford PL, Ross GT (1967) Simplified, partially automated method for radioimmunoassay of human thyroid-stimulating, growth, leuteinizing and follicle stimulating hormone. J Lab Clin Med 70: 973-980

14. Murphy BEP (1967) Some studies of the protein binding of steroids and their application to the routine micro and ultramicro measurement of various steroids in body fluids by competitive proteinbinding radioassay. J Clin Endocrinol Metab 27:973-990

15. Ahlborg G, Felig P, Hagenfeldt L, Hendler R, Wahren J (1974) Substrate turnover during prolonged exercise in man. J Clin Invest 53: 1080-1090

16. Young DR, Pelligra R, Shapira J, Adachi RR, Skrettingland K (1967) Glucose oxidation and replacement during prolonged exercise in man. J Appl Physiol 23: 734-741

17. Wahren J, Felig P, Ahlborg G, Jorfeldt L (1971) Glucose metabolism during leg exercise in man. J Clin Invest 50:2715-2725

18. Berger M, Hagg SA, Ruderman NB (1975) Glucose metabolism in perfused skeletal muscle. Interaction of insulin and exercise on glucose uptake. Biochem J 146:231-238

19. Standl E, Janka HU, Dexel T, Kolb HJ (1976) Muscle metabolism during rest and exercise: Influence on the oxygen transport system of blood in normal and diabetic subjects. Diabetes 25 (Suppl.2): 914-919

20. Vranic M, Wrenshall GA (1969) Exercise, insulin and glucose turnover in dogs. Endocrinology 85: 165-171

21. Berger M, Berchtold P, Cuppers HJ, Drost H, Kley HK, Muller WA, Wiegelmann W, Zimmermann-Telschow H, Gries FA, Kruskemper HL, Zimmerman H (1977) Metabolic and hormonal effects of muscular exercise in juvenile type diabetics. Diabetologia 13: 355-365

22. Dorchy H, Niset G, Ooms H, Poortmans J, Baran D, Loeb H (1977) Study of the coefficient of glucose assimilation during muscular exercise in diabetic adolescents deprived of insulin. Diabete Metab (Paris) 3:31-34
23. Richardson R (1934) Factors determining the effect of exercise on blood sugar in the diabetic. J Clin Invest 13:699 (Abstract)

24. Kawamori R, Vranic M (1977) Mechanism of exercise-induced hypoglycemia in depancreatized dogs maintained on long-acting insulin. J Clin Invest 59: 331-337

25. Vranic M, Kawamori R, Wrenshall GA (1974) Mechanism of exercise-induced hypoglycemia in depancreatized insulin treated dogs. Diabetes 23 (Suppl. 1): 353 (Abstract)

26. Vranic M, Kawamori R, Wrenshall GA (1975) The role of insulin and glucagon in regulating glucose turnover in dogs during exercise. In: Hormonal Responses in Exercise Symposium. Med Sci Sports 7: 27-33

27. Zinman B, Murray FT, Vranic M, Albisser AM, Liebel BS, McClean PA, Marliss EB (1977) Glucoregulation during moderate exercise in insulin treated diabetes. J Clin Endocrinol Metab 45: $641-652$

28. Lyngste J, Clausen J, Damgard S, Levin-Nielsen S, Rehfeld J, Schaffalitzky de Muckadell O, Sestoft L, Trap-Jensen J (1973) Metabolic fuels of muscle and liver in exercising normal subjects and diabetes. Excerpta Med Int Congr Ser 280:97 (Abstract)

29. Wahren J, Hagenfeldt L, Felig P (1975) Splanchnic and leg exchange of glucose amino acids and free fatty acids during exercise in diabetes mellitus. J Clin Invest 55: 1303-1314

30. Zinman B, Vranic M, Albisser AM, Leibel BS, Marliss EB (1979) The role of insulin in the metabolic response to exercise in diabetic man. Diabetes 28 (Suppl.1): 76-81

31. Murray FT, Zinman B, McClean PA, Denoga A, Albisser AM, Leibel BS, Nakhooda AF, Stokes EF, Marliss EB (1977) The metabolic response to moderate exercise in diabetic man receiving intravenous and subcutaneous insulin. $\mathrm{J}$ Clin Endocrinol Metab 44: $708-720$

32. Rennie MJ, Park DM, Sulaiman WR (1976) Uptake and release of hormones and metabolites by tissues of exercising leg in man. Am J Physiol 231: 967-973

33. Hagenfeldt L, Wahren J (1968) Human forearm muscle metabolism during exercise. III. Uptake release and oxidation of B-hydroxybutyrate and observations on the B-hydroxybutyrate/acetoacetate ratio. Scand J Clin Invest 21:314-320

Received: 1 October 1981

and in revised form: 26 May 1982

David C. Robbins, M.D.

Metabolic Unit, Department of Medicine

University of Vermont

Burlington, VT 05405, USA 